\title{
Rabies outbreak in Greece during 2012-2014: use of Geographical Information System for analysis, risk assessment and control
}

\author{
A. GIANNAKOPOULOS ${ }^{1} \dagger$, G. VALIAKOS ${ }^{1} \dagger, \mathrm{K}$. PAPASPYROPOULOS ${ }^{2}$, \\ G. DOUGAS ${ }^{3}$, L. M. KOROU ${ }^{4}$, K. E. TASIOUDI ${ }^{5}$, G. C. FTHENAKIS ${ }^{1}$, \\ M. R. HUTCHINGS ${ }^{6}$, D. KAIMARAS ${ }^{7}$, C. N. TSOKANA ${ }^{1}$, P. ILIADOU ${ }^{5}$, \\ V. SPYROU ${ }^{8}$, M. TZANI ${ }^{4}$, P. BIRTSAS ${ }^{9}$, P. KOSTOGLOU $^{4}$, C. SOKOS ${ }^{1}$,

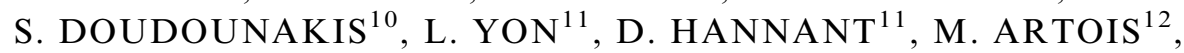 \\ S. TSIODRAS ${ }^{13}$, C. HADJICHRISTODOULOU ${ }^{3,14}$ AND C. BILLINIS ${ }^{1 *}$
}

${ }^{1}$ Faculty of Veterinary Medicine, University of Thessaly, Karditsa, Greece; ${ }^{2}$ Research Division, Hunting Federation of Macedonia and Thrace, Thessaloniki, Greece, ${ }^{3}$ Hellenic Centre for Disease Control and Prevention, Athens, Greece; ${ }^{4}$ Department of Zoonoses, Animal Health Directorate, Ministry of Rural Development and Food, Athens, Greece; ${ }^{5}$ Department of Molecular Diagnostics, FMD, Virological, Ricketsial and Exotic diseases, Athens Veterinary Centre, Ministry of Rural Development and Food, Athens, Greece; ${ }^{6}$ Disease Systems, Scotland's Rural College, Edinburgh, UK; ${ }^{7}$ Directorate of Technical Studies, Structures and Topography, Ministry of Rural Development and Food, Athens, Greece; ${ }^{8}$ Department of Animal Production, Technological Education Institute of Thessaly, Larissa, Greece; ${ }^{9}$ Department of Forestry and Natural Environment Management, Technological Institute of Thessaly, Karditsa, Greece; ${ }^{10}$ Animal Welfare Identification and Veterinary Drugs and Residues Department, Animal Health Directorate, Ministry of Rural Development and Food, Athens, Greece; ${ }^{11}$ School of Veterinary Medicine \& Science, University of Nottingham, Nottingham, UK; ${ }^{12}$ University of Lyon, VetAgro Sup, France; ${ }^{13}$ Fourth Academic Department of Internal Medicine, University of Athens Medical School, Athens, Greece; ${ }^{14}$ Faculty of Medicine, University of Thessaly, Larissa, Greece

Received 11 February 2016; Final revision 17 May 2016; Accepted 22 June 2016; first published online 20 July 2016

\section{SUMMARY}

The objectives of this work were (i) geographical analysis of the 2012-2014 outbreak of rabies in Greece using GIS and (ii) comparative analysis of animal cases with data of potential human exposure to rabies together with environmental data, in order to provide information for risk assessment, effective monitoring and control. Most animal cases (40/48) involved red foxes, while domestic animals were also diagnosed with rabies. Overall, $80 \%$ of the cases were diagnosed in central northern Greece; $75 \%$ of the cases were diagnosed in low altitudes $(<343.5 \mathrm{~m})$, within a distance of $1 \mathrm{~km}$ from human settlements. Median distance from livestock farms was $201.25 \mathrm{~m}$. Most people potentially exposed to rabies (889/1060) presented with dog bite injuries. Maximum entropy analysis revealed that distance from farms contributed the highest percentage in defining environmental niche profiles for rabid foxes. Oral vaccination programmes were implemented in 24 administrative units of the country during 2013 and 2014, covering a total surface area of $\sim 60000 \mathrm{~km}^{2}$. Rabies re-occurrence in Greece emphasizes the need for ongoing surveillance in cross-border areas and in areas with intense human activity.

Key words: Fox, Geographical Information System, Greece, rabies.

\footnotetext{
* Author for correspondence: Professor C. Billinis, Department of Microbiology and Parasitology, Faculty of Veterinary Medicine, University of Thessaly, 224 str. Trikalon, 43100, Karditsa, Greece.

(Email: billinis@vet.uth.gr)

$\dagger$ These authors contributed equally to the work and their names are listed alphabetically.
} 


\section{INTRODUCTION}

Rabies, an acute progressive disease of the central nervous system caused by neurotrophic viruses of the genus Lyssavirus, is almost always fatal in humans without timely medical care (e.g. post-exposure prophylaxis); every year, 55000 people around the world die of the disease. In Europe, rabies is found mainly in wild animals [1]. In Eastern Europe, at least four different variants of the causal virus have been described, which belong to the groups CE (Central Europe), EE (Eastern Europe), NEE (North Eastern Europe) or SF (Serbian fox) [2, 3].

Greece borders with Albania, Former Yugoslav Republic of Macedonia (FYROM), Bulgaria and Turkey. In the last three countries, rabies has been reported in wild and domestic animals and wildlife vaccination campaigns using oral live-attenuated vaccines have been implemented most recently: in Bulgaria since 2009, in FYROM since 2011 and in Turkey since 2008 [4-6]. Despite successful oral vaccination campaigns of wildlife targeting the elimination of rabies in large parts of Europe [1], the disease still occurs in the continent and, in 2012, 4884 cases were diagnosed in animals.

Prior to 1950, rabies was endemic in Greece, although there were no official records regarding frequency of the disease. During 1953 and 1954, 995 and 1135, animal rabies cases were diagnosed, respectively, as well as six and four, rabies-related human deaths, respectively. In total, during the period 1951-1980, 11472 animal rabies and 53 human rabies cases had been diagnosed. The last human case was diagnosed in 1970. Eradication of the disease has been attributed to (i) widespread vaccination of 'ownerless free-roaming' dogs, purposefully implemented, (ii) widespread, free-of-charge vaccination of domestic dogs and (iii) increased public awareness. Thereafter, only one single case of rabies was diagnosed in a hunting dog in the Evros area, near the border with Turkey, in 1987 [7, 8] (Fig. 1).

After 1987, Greece had been considered as a rabiesfree country, although there were outbreaks of the disease in neighbouring countries [8], which might have contributed to re-introduction of the disease into Greece. In November 2011, a new case of rabies was detected in FYROM, $300 \mathrm{~m}$ from the Greek border, in a dead red fox. Then, in October 2012, an outbreak of rabies was recorded within Greek territory. Since then, many cases of the disease have been diagnosed in animals, mainly in red foxes (Vulpes vulpes), in the country. Phylogenetic analysis of virus isolates showed that these belong to EE group [7].
Red foxes are adaptable omnivorous carnivores distributed across all continents in the Northern Hemisphere. They have an important ecological and socioeconomic role as a game species, as well as a key wildlife host of rabies virus [9]. Despite absence of a population estimate in Greece, red foxes are considered to have widespread distribution and high abundance in the country [10]. The adaptable and opportunistic nature of the species has enabled these animals to inhabit suburban and urban areas of Greece. Their close proximity with human populations and the resulting possible close contact of red foxes with ownerless free-roaming dogs or cats, for which there is limited management throughout Greece, support the hypothesis that red foxes are key contributors to rabies risk for public health.

The objectives of this work were (i) geographical analysis of the 2012-2014 outbreak of animal rabies in Greece using Geographical Information System (GIS) and (ii) comparative analysis of animal cases with data of potential human exposure to rabies together with environmental data, in order to provide information for risk assessment, effective monitoring and control.

\section{METHODS}

\section{Study area}

Greece borders with Albania to the northwest, FYROM and Bulgaria to the north and Turkey to the northeast. Total surface of the country is 131 $990 \mathrm{~km}^{2}$. The study area includes the local administration units, where cases of rabies have been diagnosed in animals, as well as administration units adjacent to those. The total surface of that area is $65167 \mathrm{~km}^{2}$.

Greece is characterized by (i) the presence of large mountainous areas $(\sim 80 \%$ of total surface of the country), (ii) an extensive coastline ( $15000 \mathrm{~km})$, (iii) many island complexes in the Aegean and the Ionian seas and (iv) large climatic diversity (29 climatic zones according to the Thorn Waite classification). In general, climatic conditions in the country are typically Mediterranean: summer is hot and dry and winter is usually mild. Rainfall occurs mostly in autumn and winter.

\section{Passive surveillance of the disease and cases of rabies in animals}

An existing national programme for passive surveillance of rabies, carried out according to Directive 99/2003/EC, which provides for collection and 


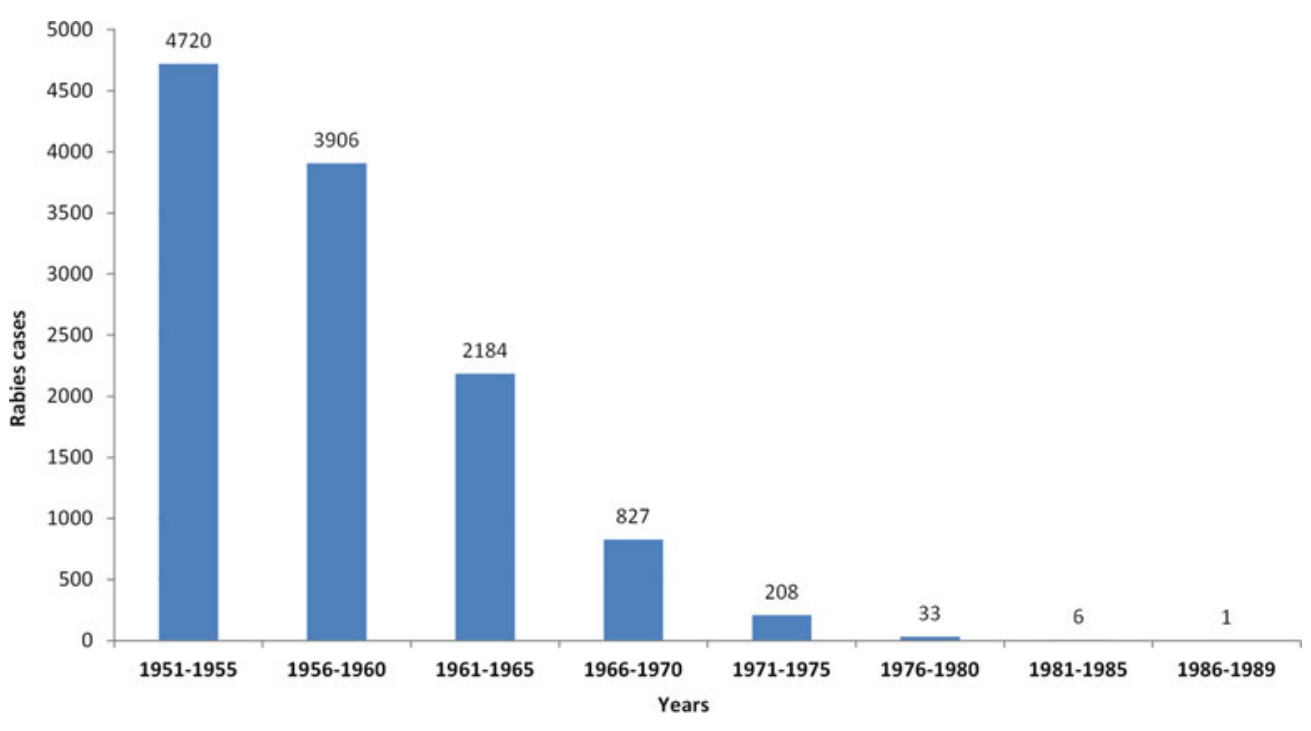

Fig. 1. Animal rabies cases diagnosed in Greece during the period 1951-1989.

examination of wild and domestic animals found dead or suspected of having rabies, was enhanced in 16 prefectures along the northern and eastern land borders of Greece, after November 2011, when a fox rabies case was officially reported by FYROM near the Northern Greek border. After laboratory confirmation of a rabid fox in October 2012 in Greece, collection of samples under the passive surveillance programme was extended in 2013 throughout the country, with the objective of achieving a more efficient surveillance of the disease and obtaining more accurate results on the circulation of the virus in the country.

Notification of suspect rabies cases according to the Greek legislation on rabies control makes it mandatory for any person working with animals (farmers, private veterinarians, staff of local authorities responsible for control of ownerless free-roaming dogs and cats, etc.) to immediately report any suspected case of rabies in animals. In addition, a public awareness campaign, conducted by the Animal Health Directorate of the Ministry of Rural Development and Food, targeted the general public, with the aim of increasing awareness and emphasizing the necessity for notification of all suspect cases. Further, game wardens and forestry officers were involved in collection of dead wild animals or animals suspected of rabies and their delivery to the competent regional veterinary authorities for subsequent appropriate submission to the national reference laboratory for animal rabies. The national rabies control and eradication programme in animals, as well as the passive surveillance programme for the disease were coordinated by the
Animal Health Directorate of the Ministry of Rural Development and Food (i.e. the official veterinary service of the country).

Details of animal rabies cases (October 2012-June 2014) and information regarding organization and implementation of the wildlife oral vaccination campaigns have been provided by the Animal Health Directorate. Laboratory diagnosis of rabies in animals is undertaken at the Athens Veterinary Centre of the Ministry of Rural Development and Food, where the Greek national reference laboratory for rabies in animals is located. Geographical coordinates of the locations, where cases of rabies were recorded, were obtained from official game wardens.

\section{Cases of human potential exposure to rabies}

Shortly after the identification of the first rabid animal, an algorithm including recommendations for management of human cases was provided to physicians. Criteria included geographical location (high-, medium-, low-risk areas), category of exposure, animal species involved, availability of the animal for evaluation in a defined time window, presentation of the animal during the incident and provoked or justified attack. Simultaneously, a notification system was established for data collection regarding human cases potentially exposed to rabies. Details of people who were potentially exposed to rabies in Greece from October 2012 to June 2014, have been provided by the Hellenic Centre for Disease Control \& Prevention (HCDCP), a service of the Ministry of 
Health. Exposure might have arisen from contact with (i) animals (wild, ownerless free-roaming or domestic) suspected to be rabies-infected or (ii) rabies vaccine baits.

Relevant data that were collected, included type of exposure, classification of exposure, animal species suspected of being rabies-infected involved (wildlife or domestic animal), location of the incident and type of anti-rabies treatment. For classification of exposure, the guidelines of the World Health Organisation were used; class III exposure involved mostly transdermal bites, single or multiple, class II exposure involved mostly minor scratches or abrasions with no bleeding and class I exposure involved touching or licking on intact skin. In relation to location of the incident, risk assessment of rabies circulation in the geographical area was also taken into account; in high-risk areas (i.e. areas within a $50 \mathrm{~km}$ radius from the location where a case of rabies was diagnosed), treatment administration was always recommended; in medium-risk areas (i. e. all other areas of administrative units in Northern Greece that were not classified as high risk), treatment administration was recommended only when, according to the description of the exposed person, the animal was considered as suspected of rabies [non-provoked attack and/or signs (as described by the person affected) compatible with rabies]; finally, in low-risk areas (i.e. all areas that were not classified as high- or mediumrisk), treatment administration was recommended only when, according to the description of the exposed person and with additional evaluation by a veterinarian, the animal was suspected of rabies (non-provoked attack and/or signs compatible with rabies).

\section{Oral anti-rabies vaccination areas}

The area where oral anti-rabies vaccination programmes had been applied, was determined by the Animal Health Directorate, in collaboration with the Directorate of Technical Studies, Structures and Topography, also a service of the Ministry of Rural Development and Food, in accordance with EU guidelines and recommendations. The selected areas included (i) a $50 \mathrm{~km}$ 'buffer zone' around the location of each laboratory-confirmed rabies case within the Greek territory, (ii) each local administrative unit where cases of animal rabies had been diagnosed and (iii) all adjacent to the above administrative units.

According to the national Greek oral rabies vaccination (ORV) programme for immunization of wildlife, which was issued before initiation of each ORV campaign and was approved by the relevant EU services, all urban and suburban areas had been excluded as target areas of vaccination. Vaccine baits were aerially distributed by fixed-wing aircraft. This method did not allow operations in areas with high-density population [11]. An additional parameter contributing to the choice of the vaccination area, was the potential of increased human exposures to the vaccine used. The vaccine selected for the first oral vaccination campaign in Greece was the SAG2 vaccine $\left(\right.$ Rabigen $^{\circledR}$ SAG2; Virbac, France), a live-attenuated rabies virus (strain SAG2) vaccine. As the vaccine contained a liveattenuated strain of the virus and there was lack of studies regarding safety of the vaccine to humans after direct contact, exposure to the vaccine required adequate postexposure rabies post-exposure prophylaxis [12]. In future vaccination campaigns, the manual distribution of vaccines within suburban areas might be examined.

\section{Environmental parameters}

Climatic variables were derived from WorldClim v. 1.4. software [13] (University of California, USA). Land uses and population density were derived from the Corine Land Cover 2000 database (European Environment Agency, Denmark). Boundaries of local administrative units were retrieved from the national open data catalogue (www.geodata.gov.gr; Institute for the Management of Information Systems, Athens, Greece). Distance from permanent water sources and altitude values were extracted from a digital elevation model (DEM). GIS layers were created to represent locations of towns and villages, distance to the nearest village, distance from water presence, road networks, wildlife refuges and livestock farms using ArcGIS v. 10.1 GIS software (ESRI, USA). All data layers were converted to a common projection, map extent and resolution, when used for MaxEnt modelling. All other environmental variables were featured data type (land uses, distance from farms, etc.), which were converted to a raster dataset with the same resolution and cell size using the conversion tool from the spatial analyst extension. All statistical analyses were performed with SPSS v. 19.0 (IBM Analytics, USA).

\section{Environmental niche model (ENM)}

In the MaxEnt modelling, the pixels of the study area defined the area, where distribution of the MaxEnt probability had been defined. Pixels with occurrence records constituted the sample points and the features 
were environmental parameters (climatic factors, vegetation, topography, etc.). The MaxEnt method requires presence-only data, utilizes both continuous and categorical data and includes efficient deterministic algorithms and mathematical definitions [14]. Red-fox rabies cases $(n=40)$ and red-fox negative samples of passive surveillance randomly selected $(n=180)$ were used as occurrence points for the ENM procedure. Maximum entropy modelling, using MaxEnt software v. 3.3.3, (Princeton University, USA), was employed to predict the appropriate ecological niches for red-fox rabies cases [14]. Goodness of fit of the model predictions was evaluated by the mean area under the curve (AUC) of the receiver-operating characteristic curve (ROC). The Jackknife procedure was used to reduce number of environmental variables to only those that showed a substantial influence on the model. According to Ceccarelli et al. [15], testing was repeated with the Jackknife procedure until all remaining variables had a positive effect on the total gain.

Descriptive statistics were extracted with frequencies and medians of the distributions. In most cases, median values were preferred instead of means, due to a non-normal distributions of the continuous variables [16]. The above data, along with coordinates of the places where rabies cases were detected in animals, were imported into the GIS environment using Arc GIS v. 10.1 software (ESRI). During spatial analysis, lakes, dams, rivers and urban areas were excluded (as vaccine baits were unnecessary and should not have been dropped near human activity areas or water supply networks). Environmental criteria for methodology of rabies vaccination (e.g. vegetation, distance from increased population density, water presence) were used to determine the area for implementation of the oral vaccination programme in each of the 24 regional units in Greece.

\section{RESULTS}

\section{Cases of rabies in animals and passive surveillance data}

In total, 48 animal rabies cases were diagnosed in Greece during the period October 2012-June 2014. Details of all cases are presented in Table 1. Most cases (40/48, 83\%) involved red foxes. Other animal species involved were dogs (five cases), cattle (two cases) and a cat.

Further, samples examined for passive surveillance purposes during the reference period originated from 956 animals: $174(18 \%)$ in 2012, $551(58 \%)$ in 2013 and $231(24 \%)$ in 2014. Of these, most samples
[488/956 (51\%), 103 in 2012, 289 in 2013 and 96 in 2014] originated from red foxes. Samples from other wild animal species examined during passive surveillance originated from bat, beech marten, brown bear, European badger, European brown hare, European wild boar, golden jackal, least weasel, mink, monkey, red squirrel, various rodent species, roe deer, wildcat and wolf. Samples also originated from domestic animal species; i.e. cat, cattle, dog, goat, horse, pig and sheep. In all cases, samples examined for passive surveillance purposes from wildlife or domestic animals as above were found negative for rabies.

Of the 74 local administrative units in Greece, cases of animal rabies had been diagnosed in eight (11\%). Of all cases, $80 \%$ were diagnosed in three administrative units in central northern Greece (Kilkis, Pella, Thessaloniki). Kilkis was the administrative unit, where most cases had been diagnosed - 18/48 (38\%) of all cases. In total, 30 large towns and 2893 smaller towns or villages were located within the $50 \mathrm{~km}$ buffer zones around each of the 48 confirmed cases of rabies. Passive surveillance samples were collected in total from $43(58 \%)$ local administrative units throughout Greece, from 22 in 2012, 38 in 2013 and 35 in 2014, from which samples had been collected. Most samples (428/956, 45\%) originated from administrative units where cases of rabies had been diagnosed. Details are presented in Table 2 and Figure 2.

Of all cases, $75 \%$ were diagnosed in locations with an altitude of $<343.5 \mathrm{~m}$ and within a distance of $1 \mathrm{~km}$ from human settlements. Median altitude of locations where cases occurred, was $228 \mathrm{~m}$ (range 10-1076 m) above sea level (Table 3, Fig. 3). Further, $50 \%$ of all cases were detected within a distance of $201 \mathrm{~m}$ from a body of water, $75 \%$ of all cases were detected within $350 \mathrm{~m}$ of wildlife refuges and $75 \%$ of all cases within $351 \mathrm{~m}$ from a provincial road and $517 \mathrm{~m}$ from a forest road network (Table 3).

Samples for passive surveillance were collected from locations with a mean altitude of $354 \mathrm{~m}$ (range 0-1492 m). In particular, samples from red foxes were collected from locations with a mean altitude of $391 \mathrm{~m}$ (range $0-1476 \mathrm{~m}$ ), within a distance of $1612 \mathrm{~m}$ (range 100-12600 m) from a human settlement; samples from dogs were collected from a mean altitude of $248 \mathrm{~m}$ (range $0-1123 \mathrm{~m}$ ).

Most cases $(52 \%)$ of rabies occurred in cultivated land. Cases were also recorded in natural areas (forests, shrub land, agroforestry formations) (29\% of all), as well as in human settlements or surrounding areas $(19 \%)$. Mean distance of locations where a 
Table 1. Details, in chronological order, of confirmed cases of rabies in animals in Greece (October 2012-June 2014)

\begin{tabular}{|c|c|c|c|c|}
\hline Case ID & Animal species involved & Date of occurrence & Administrative unit & Location \\
\hline 1 & Red fox & 19 Oct. 2012 & Kozani & Siatista \\
\hline 2 & Dog & 19 Nov. 2012 & Kastoria & Ieropigi \\
\hline 3 & Red fox & 7 Dec. 2012 & Kilkis & Metaksoxori \\
\hline 4 & Red fox & 12 Dec. 2012 & Kilkis & Kato Potamia \\
\hline 5 & Dog & 20 Dec. 2012 & Pella & Aridaia \\
\hline 6 & Red fox & 24 Dec. 2012 & Pella & Aridaia \\
\hline 7 & Red fox & 31 Dec. 2012 & Kilkis & Metalliko \\
\hline 8 & Red fox & 31 Dec. 2012 & Kilkis & Stavrochori \\
\hline 9 & Red fox & 31 Dec. 2012 & Pella & Loutraki \\
\hline 10 & Red fox & 14 Jan. 2013 & Kilkis & Kilkis \\
\hline 11 & Red fox & 18 Jan. 2013 & Kilkis & Antigonia \\
\hline 12 & Red fox & 31 Jan. 2103 & Kilkis & Koromilia \\
\hline 13 & Red fox & 20 Feb. 2013 & Kozani & Kteni \\
\hline 14 & Cat & 28 Feb. 2013 & Trikala & Agrielis \\
\hline 15 & Red fox & 28 Feb. 2013 & Kilkis & Koromilia \\
\hline 16 & Red fox & 11 Mar. 2013 & Kilkis & Vafeioxori \\
\hline 17 & Red fox & 13 Mar. 2013 & Kilkis & Xorigi \\
\hline 18 & Red fox & 22 Mar. 2013 & Trikala & Kastraki \\
\hline 19 & Red fox & 1 Apr. 2013 & Kilkis & Parocthio \\
\hline 20 & Red fox & 11 Apr. 2013 & Trikala & Platanos \\
\hline 21 & Red fox & 22 Apr. 2013 & Kilkis & Koromilia \\
\hline 22 & Red fox & 29 May 2013 & Pella & Idraia \\
\hline 23 & Red fox & 6 June 2013 & Thessaloniki & Sindos \\
\hline 24 & Dog & 18 June 2013 & Serres & Emmanouil Pappas \\
\hline 25 & Red fox & 5 July 2013 & Pella & Piperia \\
\hline 26 & Red fox & 24 July 2013 & Kilkis & Lipsidrio \\
\hline 27 & Red fox & 7 Aug. 2013 & Kilkis & Kolchida \\
\hline 28 & Red fox & 28 Aug. 2013 & Pella & Mayrovouni \\
\hline 29 & Red fox & 4 Oct. 2013 & Thessaloniki & Nea Filadelphia \\
\hline 30 & Red fox & 10 Oct. 2013 & Thessaloniki & Drymos \\
\hline 31 & Red fox & 10 Oct. 2013 & Thessaloniki & Proxoma \\
\hline 32 & Red fox & 16 Oct. 2013 & Pella & Orma \\
\hline 33 & Red fox & 17 Oct. 201 & Kilkis & Pirgotos \\
\hline 34 & Red fox & 24 Oct. 2013 & Thessaloniki & Mellisochori \\
\hline 35 & Red fox & 1 Nov. 2013 & Pella & Orma \\
\hline 36 & Cattle & 20 Nov. 2013 & Kilkis & Miriophyto \\
\hline 37 & Cattle & 22 Nov. 2013 & Kilkis & Miriophyto \\
\hline 38 & Red fox & 19 Dec. 2013 & Pella & Neochori Almopias \\
\hline 39 & Red fox & 9 Jan. 2014 & Kilkis & Mayroneri \\
\hline 40 & Red fox & 15 Jan. 2014 & Thessaloniki & Modi \\
\hline 41 & Red fox & 15 Jan. 2014 & Thessaloniki & Euaggelismos Laggada \\
\hline 42 & Red fox & 15 Jan. 2014 & Thessaloniki & Neochorouda \\
\hline 43 & Red fox & 15 Jan. 2014 & Thessaloniki & Vasiloudi \\
\hline 44 & Dog & 16 Jan. 2014 & Thessaloniki & Oraiokastro \\
\hline 45 & Dog & 26 Feb. 2014 & Larissa & Elassona \\
\hline 46 & Red fox & 17 Mar. 2014 & Trikala & Agios Nikolaos \\
\hline 47 & Red fox & 31 Mar. 2014 & Trikala & Nea Pefki \\
\hline 48 & Red fox & 12 May 2014 & Pella & Orma \\
\hline
\end{tabular}

case occurred, from a livestock farm was $201 \mathrm{~m}$ (range $0-2101 \mathrm{~m}$ ). Of all cases, $73 \%$ occurred in areas with increased livestock density and grazing activities according to the kernel density estimator.

\section{Predictive ENM for red-fox rabid cases}

The environmental variable with highest gain when used in isolation was annual precipitation, which 
Table 2. Geographical locations of cases of rabies diagnosed in Greece and of animals from which samples were collected for surveillance purposes (October 2012June 2014)

\begin{tabular}{|c|c|c|}
\hline $\begin{array}{l}\text { Administrative } \\
\text { unit }\end{array}$ & $\begin{array}{l}\text { Rabies } \\
\text { cases } \\
n(\%)\end{array}$ & $\begin{array}{l}\text { Samples collected } \\
\text { for surveillance } \\
\text { purposes, } n(\%)\end{array}$ \\
\hline Kilkis & $18(38)$ & $64(6 \cdot 5)$ \\
\hline Thessaloniki & $10(21)$ & $102(10 \cdot 5)$ \\
\hline Pella & $10(21)$ & $40(4)$ \\
\hline Trikala & $5(10)$ & $15(1 \cdot 5)$ \\
\hline Kozani & $2(4)$ & $81(8 \cdot 5)$ \\
\hline Kastoria & $1(2)$ & $43(4 \cdot 5)$ \\
\hline Larisa & $1(2)$ & $8(1)$ \\
\hline Serres & $1(2)$ & $75(8)$ \\
\hline Ioannina & 0 & $65(7)$ \\
\hline Drama & 0 & $54(5 \cdot 5)$ \\
\hline Evros & 0 & $54(5 \cdot 5)$ \\
\hline Florina & 0 & $54(5 \cdot 5)$ \\
\hline Attiki & 0 & $39(4)$ \\
\hline Grevena & 0 & $36(4)$ \\
\hline Pieria & 0 & $25(2 \cdot 5)$ \\
\hline Xanthi & 0 & $24(2 \cdot 5)$ \\
\hline Kavala & 0 & $23(2 \cdot 5)$ \\
\hline Halkidiki & 0 & $22(2 \cdot 5)$ \\
\hline Karditsa & 0 & $20(2)$ \\
\hline Rodopi & 0 & $19(2)$ \\
\hline Thesprotia & 0 & $18(2)$ \\
\hline Imathia & 0 & $8(1)$ \\
\hline Preveza & 0 & $8(1)$ \\
\hline Evia & 0 & $7(0 \cdot 5)$ \\
\hline Arta & 0 & $6(0 \cdot 5)$ \\
\hline Viotia & 0 & $6(0 \cdot 5)$ \\
\hline Lefkada & 0 & $5(0 \cdot 5)$ \\
\hline Aetoloakarnania & 0 & $4(0 \cdot 5)$ \\
\hline Ilia & 0 & $4(0 \cdot 5)$ \\
\hline Lakonia & 0 & $4(0 \cdot 5)$ \\
\hline Magnisia & 0 & $4(0 \cdot 5)$ \\
\hline Evritania & 0 & $3(0 \cdot 5)$ \\
\hline Fokida & 0 & $3(0 \cdot 5)$ \\
\hline Argolida & 0 & 2 \\
\hline Fthiotida & 0 & 2 \\
\hline Messinia & 0 & 2 \\
\hline Ahaia & 0 & 1 \\
\hline Arkadia & 0 & 1 \\
\hline Hania & 0 & 1 \\
\hline Iraklio & 0 & 1 \\
\hline Korinthia & 0 & 1 \\
\hline Dodecanisa & 0 & 1 \\
\hline Rethymno & 0 & 1 \\
\hline Total & $48(100)$ & $956(100)$ \\
\hline
\end{tabular}

therefore appeared to have the most useful information by itself. The environmental variable that decreased gain the most when it was omitted, was distance from farms, which therefore appeared to have most information that was not present in other variables. Regularized training gain was $2 \cdot 047$, training AUC was 0.943 and unregularized training gain was 2.459. Maximum entropy analysis in the region of Kilkis, where most cases of the disease were recorded, revealed that relative contribution of environmental variables included cultivated land in combination with livestock activity. Regularized training gain was 1.536, training AUC was 0.921 and unregularized training gain was $2 \cdot 008$.

\section{Exposure of humans to rabies}

The HCDCP recorded a total of 1060 people, who were potentially exposed to rabies from October 2012 to June 2014. Of these, 889 people presented following a dog bite. In most cases, exposure involved ownerless free-roaming dogs $(65 \%)$, while ownerless free-roaming cats were involved less often ( $8 \%$ ); also, $11(1 \%)$ people had reportedly come into direct or indirect contact with vaccine baits. Details are given in Table 4. Further, 721 (68\% of all) people had reported type III exposure, $310(29 \%)$ type II and 19 (2\%) type I exposure, while no information regarding type of exposure was available for $10(1 \%)$ people.

Most cases of anti-rabies treatment were administered to people in areas, where rabies animal cases had also been reported. Anti-rabies treatment administered to potentially exposed people included: vaccine administration (578 people, $54 \cdot 5 \%$ ), vaccine and anti-serum administration (462 people, $43.5 \%$ ) or rabies anti-serum administration (20 people, $2 \%$ ). In some cases, anti-serum administration was initiated while vaccine was not readily available but soon after, the implicated animal was evaluated as free of clinical signs or tested negative for rabies and prophylactic treatment was then discontinued without the addition of vaccine. In relation to year of administration, anti-rabies treatment was given to $22(2 \%)$ people in 2012, to $574(54 \%)$ people in 2013 and to $464(44 \%)$ people in 2014.

\section{Oral anti-rabies vaccination programme}

In 2013 and 2014, oral anti-rabies vaccination programmes were implemented in 24 local administrative units, where animals had been considered to be at increased risk for infection and disease. Total surface of the area, where the oral anti-rabies vaccination was performed, was $\sim 60000 \mathrm{~km}^{2}$. Average density of 


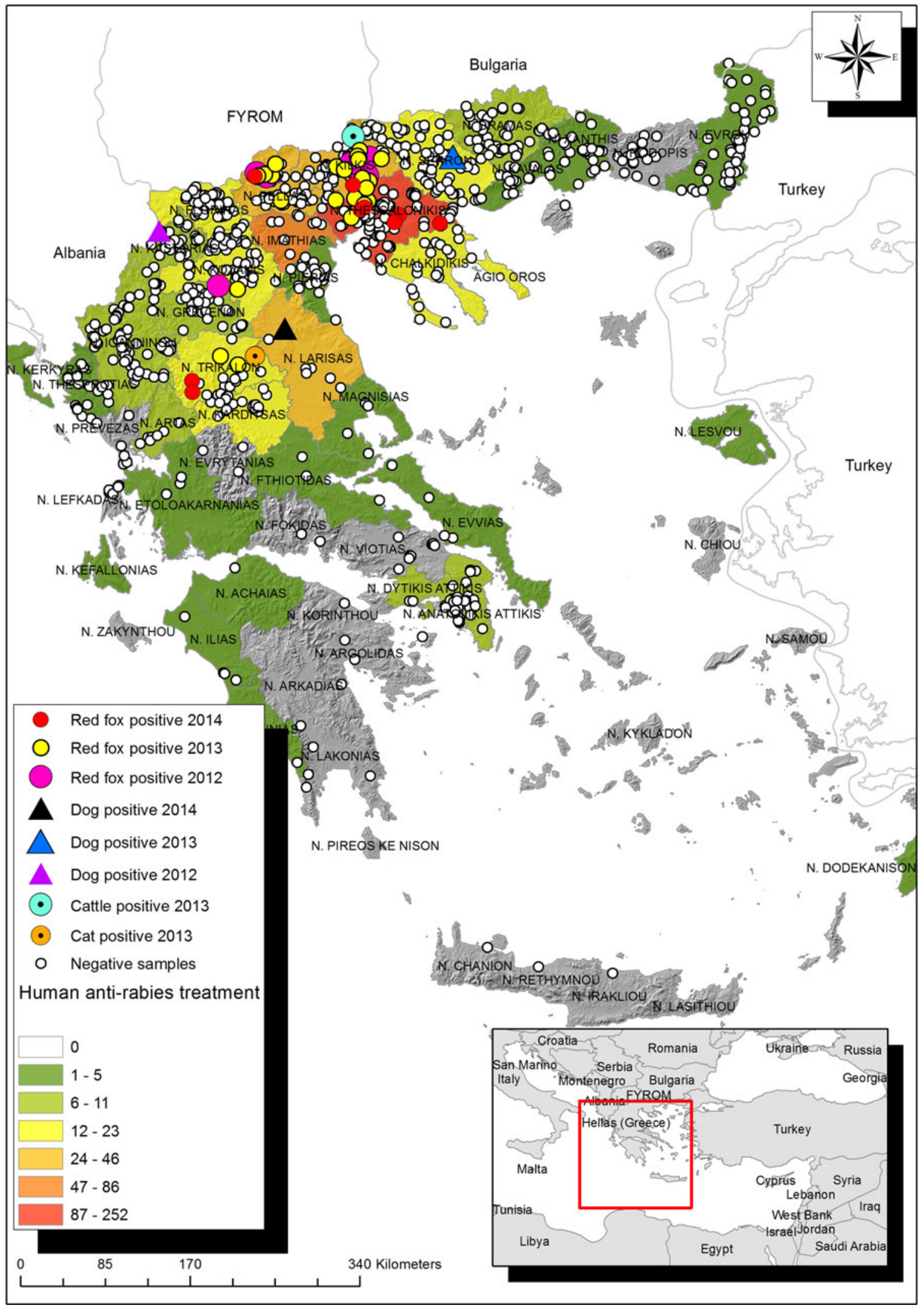

Fig. 2. Map of geographical location of animal rabies cases diagnosed in Greece in conjunction with the negative animal samples of the passive surveillance and the rabies post-exposure prophylaxis in humans (October 2012-June 2014). 
Table 3. Environmental parameters in locations, where cases of rabies in animals had been diagnosed in Greece (October 2012-June 2014)

\begin{tabular}{lll}
\hline \hline Parameter & Median & Range \\
\hline Annual rainfall $(\mathrm{mm})$ & $467 \cdot 50$ & $440 \cdot 00-$ \\
& & $917 \cdot 00$ \\
Temperature $\left({ }^{\circ} \mathrm{C}\right)$ & $14 \cdot 05$ & $9 \cdot 50-15 \cdot 80$ \\
Distance from water $(\mathrm{m})$ & $660 \cdot 9$ & $0 \cdot 00-2898 \cdot 2$ \\
Altitude $(\mathrm{m})$ & $227 \cdot 50$ & $10 \cdot 00-$ \\
& & $1076 \cdot 00$ \\
Distance from human settlement & $291 \cdot 42$ & $0 \cdot 00-3759 \cdot 00$ \\
(m) & & \\
Distance from wildlife refuge (m) & $190 \cdot 00$ & $0 \cdot 00-927 \cdot 07$ \\
Distance from forest road (m) & $284 \cdot 61$ & $0 \cdot 00-1440 \cdot 00$ \\
Distance from provincial road (m) & $190 \cdot 00$ & $0 \cdot 00-927 \cdot 00$ \\
Distance from livestock farm (m) & $201 \cdot 25$ & $0-2101 \cdot 00$ \\
Livestock index & $0 \cdot 76$ & $0 \cdot 33-2 \cdot 95$ \\
\hline \hline
\end{tabular}

distributed baits, was $22-25$ baits $/ \mathrm{km}^{2}$, depending on surface factors and year of the campaign.

\section{DISCUSSION}

\section{Re-emergence of rabies in animals in Greece}

Animal rabies re-emerged in Greece in 2012. The outbreak of the disease depended upon the situation in neighbouring countries, all of which had reported animal rabies cases in the years previous to the outbreak year $[6,17,18]$. In fact, there is a geographical similarity, in terms of altitude and land use, of the area of Kilkis (a border administrative unit of the country) with the respective unit Selemli in FYROM, where a rabid red fox was diagnosed in 2011. Results of relevant studies have confirmed phylogenetic similarity of the Greek rabies viral strains with strains of the virus from rabies cases in FYROM, Bulgaria, Bosnia \& Herzegovina, Montenegro and Serbia [7]. These findings, allied to the location of the initial cases of the disease, i.e. close to the north boundary of the country, support a hypothesis of southwards expansion of the disease from the Balkan countries. This hypothesis could be supported by the fact that mountains can form a substantial barrier to the spread of foxes into a territory, hence this could be a reason for the southwards spread of the disease, from FYROM into Greece, rather than into other areas of that country. However, identification of rabies at high altitudes, recently described in Bulgaria and Italy $[5,19]$ highlights the permeability of natural barriers. Although red foxes, the most important reservoir for maintenance of rabies in wildlife in Central or South Europe [2, 20-23] are well-suited to a wide range of landscapes and can potentially spread rabies in every type of environment, the majority of rabid red foxes (16/40) were recorded in the area of Kilkis at a mean altitude of $210 \cdot 1 \mathrm{~m}$. Thus, it seems that landscape configuration characterized by gentle slopes influenced animal movement and rabies dissemination. Rabies dissemination has occurred through fox social structures and the wider dispersal of young foxes. This may be further affected by a complex interaction of various factors, including environmental parameters, e.g. landscape configuration (shape of available habitat, terrain roughness, disturbance, etc.), which relate to dispersal of wildlife.

Sporadically, rabies can spill over from wildlife to domestic animals, which may then attack people. In general, ownerless free-roaming dogs were responsible for the majority of cases of potential virus transmission to humans $(65 \%$ of cases with treatment administration). In Greece large and unrecorded numbers of ownerless free-roaming dogs live in urban areas. Legal framework endorses reproductive-only control schemes along with education of owners. Municipal authorities are responsible by law for the management of urban free-roaming animals including the postexposure procedure of search, capture and prompt evaluation of the involved animal. High number of incidents and lack of available resources pose significant limitations in performing the above-mentioned tasks. Voluntary animal welfare societies collaborate with local authorities and contribute to reproductive control and animal welfare issues.

Most cases of the disease have been recorded in areas of low altitude: agricultural land close to human settlements. The maximum entropy analysis revealed that distance from farms contributed the highest proportion in defining environmental niche profiles for rabid foxes. Notification of suspected rabies cases was, according to the national rabies control and eradication programme, mandatory for all parties involved. Forestry officers and game wardens (who, due to the nature of their duties, mostly operate at high altitudes) were involved in collection of dead animals and delivery to regional veterinary officers. Further, cultivated land in combination with habitats offering cover (i.e. forests, shrub land, agroforestry formations) constituted $81 \%$ of the buffer zones surrounding the locations of rabies cases. Maximum entropy analysis conducted specifically in the area of Kilkis, where most cases of rabies in foxes were 


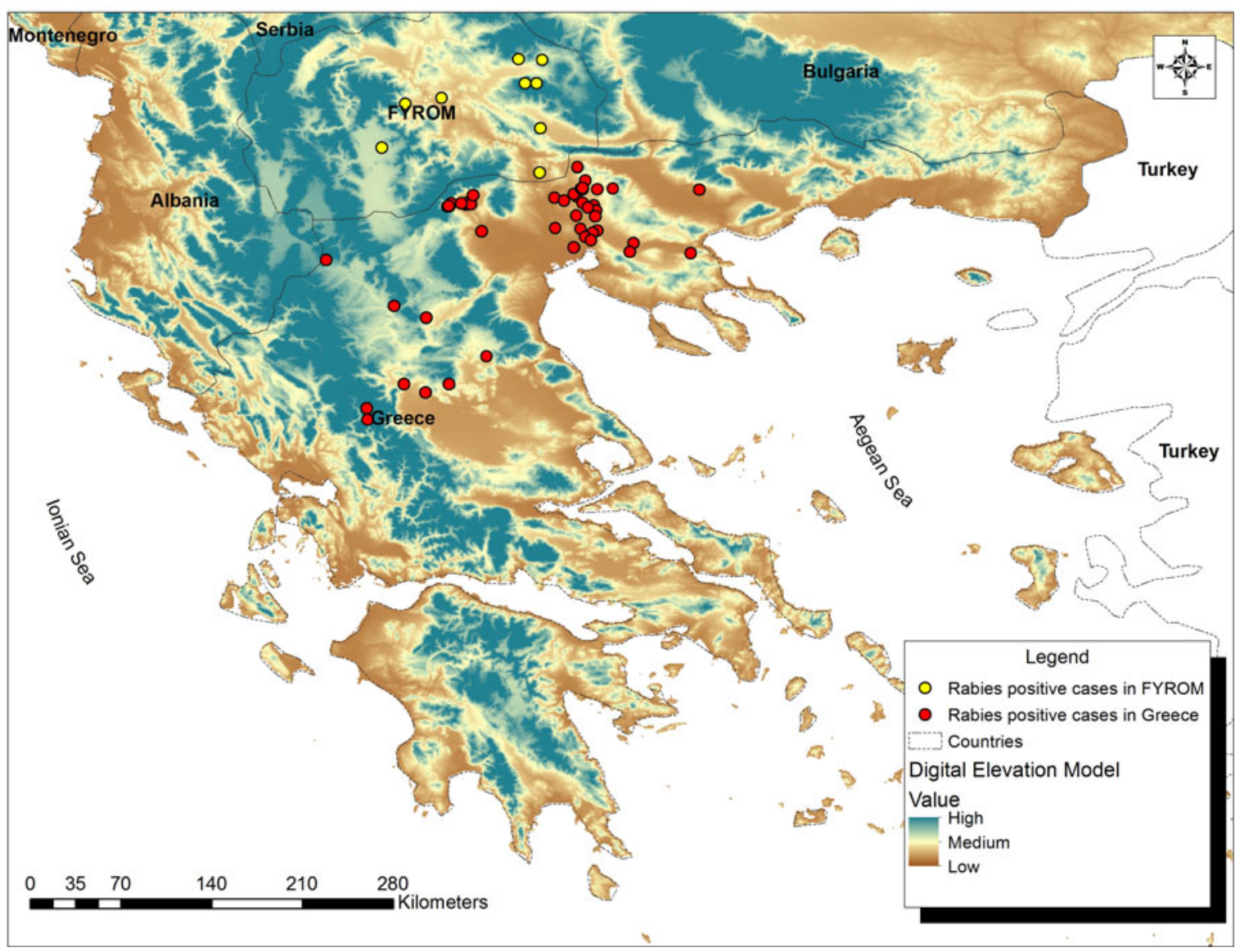

Fig. 3. Map of geographical location of animal rabies cases diagnosed in Greece and the Former Yugoslav Republic of Macedonia (FYROM), in relation to topographic configuration at landscape level.

recorded, revealed that cultivated land in combination with livestock activity made the highest contribution in the environmental niche profiles for rabid foxes, a finding consistent with known fox ecology [24].

\section{Potential for transmission of rabies to people}

Incidence of rabies in humans in Europe remains extremely small $(<5$ cases yearly). No human cases have been reported in Greece during the current outbreak in animals, a result of applying strict preventive and effective control measures of rabies in domesticated animals, as well as in the wild animal population.

Management of human exposure cases during the outbreak presented some difficulties because of (i) the large numbers of exposed people to whom treatment should have been administered, and (ii) the frequent unavailability of the animal (often ownerless free-roaming dogs or cats) involved in the incident for detailed veterinary examination. These reasons have led to increased numbers of treatment cases of people during the rabies outbreak. Nevertheless, cases of potential exposure after biting by domestic carnivores (dogs, cats) have also been reported, which calls for implementation of compulsory vaccinations of these animals and of proper education of owners and attack victims for post-exposure procedures (i.e. exchange of contact details, veterinary evaluation).

Certain criteria were set from Competent Health Authorities in the form of an algorithm to guide physicians regarding the need to administer post-exposure prophylactic anti-rabies treatment in potentially exposed humans. Due to the fact that a universal algorithm may not include every single parameter due to complexity issues, physicians were encouraged to individualize, as far as possible, each case bearing in mind that irrational administration of treatments may result in unnecessary side-effects and even exhaust available consumables. This could explain the fact that postexposure prophylactic treatments were administered 
Table 4. Details of reported source of exposure of humans, who received post-exposure prophylactic anti-rabies treatment

\begin{tabular}{lll}
\hline \hline $\begin{array}{l}\text { Source of potential exposure/ } \\
\text { details }\end{array}$ & $\begin{array}{l}\text { No. of } \\
\text { cases }\end{array}$ & $\begin{array}{l}\text { Proportion } \\
\text { (of all cases) }\end{array}$ \\
\hline Animals & 1048 & $99 \%$ \\
Dog & 889 & $84 \%$ \\
$\quad$ Ownerless free-roaming & 690 & $65 \%$ \\
$\quad$ Domestic & 135 & \\
$\quad$ Farm & 38 & \\
$\quad$ Hunting & 11 & \\
Not reported & 15 & \\
Cat & 95 & $10 \%$ \\
$\quad$ Ownerless free-roaming & 81 & $8 \%$ \\
$\quad$ Domestic & 14 & \\
Red fox & 26 & \\
Other animal species & 38 & \\
Bat & 16 & \\
Stone marten & 5 & \\
Cattle & 3 & \\
Mouse/rat & 3 & \\
Wild boar & 3 & \\
Brown bear & 2 & \\
Horse & 2 & \\
Golden jackal & 1 & \\
Pig & 1 & \\
Weasel & 1 & \\
Wolf & 1 & \\
Vaccine bait & 11 & \\
Direct contact & 7 & \\
Indirect contact (with dog & 4 & \\
that consumed bait) & & \\
Unknown & 1,060 & \\
Total & & \\
\hline \hline
\end{tabular}

to humans even in areas far away and well-isolated from the locations of clinical cases of rabies.

\section{Oral anti-rabies vaccination programme}

Oral vaccination of foxes is a proven, effective method for elimination of rabies in the wildlife population. In Europe, 24 countries have already implemented oral vaccination of foxes [25]. Many countries (Bosnia \& Herzegovina, Bulgaria, Croatia, Czech Republic, Estonia, FYROM, Germany, Kosovo, Montenegro, Poland, Romania, Serbia, Slovenia) have reported a significant reduction of incidence risk or elimination of rabies after implementation of oral vaccination campaigns [18, 26-36]. Oral vaccination of foxes has been considered successful if the number of rabies cases is reduced by over $90 \%$ in a period up to 10 years after initiation, although, in many countries, this target has been achieved during a period of 5 years [25].

Extent of the outbreak indicates the need for a prevalence estimate of the virus circulation in wild animals in northern Greece [8], for correct implementation of preventive measures to control further expansion of the disease. Moreover, increased passive surveillance throughout the country will be necessary to detect any possible new cases of the disease.

\section{Concluding remarks}

Application of an oral vaccination programme of wildlife and mandatory vaccination of domestic animals has contributed to limiting the disease, with no new cases since 2014. Implementation of oral vaccination campaigns of red foxes for a number of subsequent years will ensure eradication of the disease in wildlife and will contribute to the rabies-free status of the country in the future. Rabies reoccurrence in Greece emphasizes the need for ongoing passive and active surveillance for important zoonotic diseases, even when these are believed to have been eradicated. Enhanced passive surveillance in the cross-border areas and in areas with intense human activity will permit early detection of new cases. Multidisciplinary cooperation of medical and veterinary authorities and institutes is necessary for the collection of all data required for the implementation of appropriate disease control and elimination measures.

\section{ACKNOWLEDGEMENTS}

Part of the outcomes of this research, conducted at the Faculty of Veterinary Medicine of the University of Thessaly, received partial funding from the European Union Seventh Framework Programme (2007-2013) under grant agreement no. 222633 (Wild Tech). Scotland's Rural College (SRUC) receives support from the Scottish Government. The costs related to the passive surveillance of the disease (samples analysis) as well as the costs for the implementation of the oral rabies vaccination campaigns were co-financed by the European Commission and the Greek state budget.

\section{DECLARATION OF INTEREST}

None. 


\section{REFERENCES}

1. Cliquet F, Aubert M. Elimination of terrestrial rabies in Western European countries. Developments in Biologicals 2004; 119: 185-204.

2. Bourhy $\mathbf{H}$, et al. Ecology and evolution of rabies virus in Europe. Journal of General Virology 1999; 80: 2545-2557.

3. McElhinney LM, et al. Molecular diversity and evolutionary history of rabies virus strains circulating in the Balkans. Journal of General Virology 2011; 92: 2171-2180.

4. Picard-Meyer E, et al. Molecular characterisation of rabies virus strains in the Republic of Macedonia. Archives of Virology 2013; 158: 237-240.

5. Robardet E, et al. Epidemiology and molecular diversity of rabies viruses in Bulgaria. Epidemiology and Infection 2014; 142: 871-877.

6. Un H, et al. Oral vaccination of foxes against rabies in Turkey between 2008 and 2010. Berliner Und Münchener Tierärztliche Wochenschrift 2012; 125: 203-208.

7. Tasioudi KE, et al. Recurrence of animal rabies, Greece, 2012. Emerging Infectious Diseases 2014; 20: 326-328.

8. Tsiodras $\mathbf{S}$, et al. Re-emergence of animal rabies in northern Greece and subsequent human exposure, October 2012-March 2013. Eurosurveillance 2013; 18: 20474.

9. Galov A, et al. High genetic diversity and low population structure in red foxes (Vulpes vulpes) from Croatia. Mammalian Biology-Zeitschrift für Säugetierkunde 2014; 79: 77-80.

10. Birtsas P, Sokos C, Exadactylos S. Carnivores in burned and adjacent unburned areas in a Mediterranean ecosystem. Mammalia 2012; 76.

11. Korou L-M, et al. Evaluation of the first oral rabies vaccination campaign of the red foxes in Greece. Vaccine 2016; 34: 41-48.

12. Mähl P, et al. Twenty year experience of the oral rabies vaccine SAG2 in wildlife: a global review. Veterinary Research 2014; 45: 77.

13. Hijmans RJ, et al. Very high resolution interpolated climate surfaces for global land areas. International Journal of Climatoloy 2005; 25: 1965-1978.

14. Phillips SJ, Anderson RP, Schapire RE. Maximum entropy modeling of species geographic distributions. Ecological Modelling 2006; 190: 231-259.

15. Ceccarelli S, et al. Modelling the potential geographic distribution of triatomines infected by Triatoma virus in the southern cone of South America. Parasites \& Vectors 2015; 8: 153.

16. Gray CD, Kinnear PR. IBM SPSS Statistics 19 Made Simple. Hove, UK: Psychology Press, 2012.

17. Kirandjiski T, et al. First reported cases of rabies in the Republic of Macedonia. Veterinary Record 2012; 170: 312.

18. Ilieva D. Assessment of the efficiency of oral vaccination against rabies in the fox population in Bulgaria. Revue de Médecine Vétérinaire 2013; 11: 521-527.

19. Mulatti P, et al. Emergency oral rabies vaccination of foxes in Italy in 2009-2010: identification of residual rabies foci at higher altitudes in the Alps. Epidemiology and Infection 2012; 140: 591-598.
20. Pastoret PP, Brochier B. Epidemiology and elimination of rabies in western Europe. Veterinary Journal 1998; 156: 83-90.

21. Finnegan CJ, et al. Rabies in North America and Europe. Journal of the Royal Society of Medicine 2002; 95: 9-13.

22. Wandeler A. Epidemiology and ecology of fox rabies in Europe. In: World Organisation for Animal Health, eds. Historical Perspective of Rabies in Europe and the Mediterranean Basin. Paris, France: OIE, 2004, pp. 201-214.

23. Aikimbayev A, et al. Fighting rabies in Eastern Europe, the Middle East and Central Asia - experts call for a regional initiative for rabies elimination. Zoonoses and Public Health 2014; 61: 219-226.

24. Steck F, et al. Oral immunisation of foxes against rabies. A field study. Journal of Veterinary Medicine, Series B 1982; 29: 372-396.

25. Freuling CM, et al. The elimination of fox rabies from Europe: determinants of success and lessons for the future. Philosophical Transactions of the Royal Society of London, Series B, Biological Sciences 2013; 368: 20120142.

26. Smreczak M, et al. Rabies surveillance in Poland (19922006). Developments in Biologicals 2008; 131: 249-256.

27. Hostnik P, et al. Control of rabies in Slovenia. Journal of Wildlife Diseases 2006; 42: 459-465.

28. Matouch O, et al. Elimination of rabies in the Czech Republic. Developments in Biologicals 2006; 125: 141-143.

29. Cliquet F, et al. Eliminating rabies in Estonia. PLoS neglected tropical diseases 2012; 6: e1535.

30. Müller $\mathbf{T}$, et al. Elimination of terrestrial rabies in Germany using oral vaccination of foxes. Berliner und Münchener Tierärztliche Wochenschrift 2012; 125: 178-190.

31. European Commission. Report on the task force meeting of the rabies subgroup. Zagreb, Croatia: European Commission, Health and Consumers Directorate-general, Directorate $\mathrm{G}$ - Veterinary and International Affairs, Unit G5: Veterinary programmes, 2012.

32. European Commission. Programme for Surveillance, Control and Eradication of Rabies in Romania 2012. European Commission, Health and Consumers Directorate-general, Directorate $\mathrm{G}$-Veterinary and International Affairs, Unit G5: Veterinary programmes, 2012.

33. Potzsch CJ, et al. Rabies in Montenegro: transboundary disease control from a small country's perspective. In: Proceedings of the 13th International Symposium on Veterinary Epidemiology and Economics. Belgium, Netherlands; International Symposia on Veterinary Epidemiology and Economics, 2012, pp. 232.

34. Tosic K, et al. Oral vaccination of foxes: principle and field application. Veterinary Journal of Republic of Srpska 2013; XIII: 237-244.

35. Yakobson B, et al. Implementation and monitoring of oral rabies vaccination of foxes in Kosovo between 2010 and 2013 - an international and intersectorial effort. International Journal of Medical Microbiology 2014; 304: 902-910.

36. Lupulovic D, et al. First report on the efficiency of oral vaccination of foxes against rabies in Serbia. Zoonoses and Public Health 2015; 62: 625-636. 